\title{
A Comparative Study between Dexmedetomidine versus Fentanyl on Intubating Conditions and Side Effects during Awake Fiberoptic Nasal Intubation under Topical Anesthesia in Patients Underwent Elective Surgical Operation
}

\author{
Ayman Eldemrdash', Nagwa Gamaledeen', Zaher Zaher'1, Abdl Aal Salem² \\ ${ }^{1}$ Department of Anesthesia, Faculty of Medicine, Aswan University, Aswan, Egypt \\ ${ }^{2}$ Department of General Surgery, Faculty of Medicine, Aswan University, Aswan, Egypt \\ Email: aymaneldemrdash@yahoo.com,nagwamgamal@yahoo.com,Zahora2020@yahoo.com,dr.abdelaal@yahoo.com
}

How to cite this paper: Eldemrdash, A., Gamaledeen, N., Zaher, Z. and Salem, A.A. (2017) A Comparative Study between Dexmedetomidine versus Fentanyl on Intubating Conditions and Side Effects during Awake Fiberoptic Nasal Intubation under Topical Anesthesia in Patients Underwent Elective Surgical Operation. Open Journal of Anesthesiology, 7, 415-425.

https://doi.org/10.4236/ojanes.2017.712043

Received: November 15, 2017

Accepted: December 26, 2017

Published: December 29, 2017

Copyright $\odot 2017$ by authors and Scientific Research Publishing Inc. This work is licensed under the Creative Commons Attribution International License (CC BY 4.0).

http://creativecommons.org/licenses/by/4.0/

\begin{abstract}
Awake fiber optic intubation is the gold standard technique for management of anticipated difficult airway. In spite of availability of several sedatives, at higher doses these drugs cause respiratory depression and sensorium. This study was conducted to evaluate and compare the efficacy of Dexmedetomidine or Fentanyl for sedation during AFOI. Sixty patients, aged 20 - 40 years undergoing AFOI were made into two groups, group D Dexmedetomidine 1 $\mathrm{mcg} / \mathrm{kg}$, and group F Fentanyl $2 \mu \mathrm{g} / \mathrm{kg}$, both drugs was diluted with $50 \mathrm{ml} \mathrm{sa-}$ line to be infused over 10 minutes). Demographic data, patient cough score, sedation score and post-intubation score were compared between two groups. Cough score $\leq 2$ was 25 patients in group D compared with 2 patients in group F, post intubation score 1 in group D was 24 vs. 2 in group F, mean Ramsy sedation score in group D was $\mathbf{3}$ vs. 2.1 in group $\mathrm{F}, \mathrm{SpO}_{2} \geq 95 \%$ in group D was 28 vs. 5 patients in group F, insignificant rise in MAP from 93 to $96 \mathrm{mmhg}$ in group $\mathrm{D}(\mathrm{P}=0.347)$, but there was significant rise from 92.3 to $118.18(\mathrm{P} \leq 0.0001)$ in group $\mathrm{F}$, there was significant decrease in HR from 77.4 to $71(\mathrm{P}=0.005)$ vs. significant rise from 77 to $114(\mathrm{P} \leq 0.0001)$ in group $\mathrm{F}$. Thus, we can conclude that Dexmedetomidine provides better intubating condition, sedation, less respiratory depression and hemodynamic stability than fentanyl for AFOI, without adversely affecting airway.
\end{abstract}




\section{Keywords}

Dexmedetomidine, Fentanyl, Intubation, Awake Fiberoptic, Sedation, Intravenous

\section{Introduction}

Awake fiberoptic intubation (AFOI) is recommended for patients with anticipated difficult airway and has become the accepted gold standard technique for management of recognized difficult airway [1]. Adequate sedation is an essential part of any awake intubation. It is expected that an ideal sedative drug for awake intubation should ensure that the patient maintain spontaneous ventilation and remains reasonably conscious to protect the airway, while at the same time it must keep the patient co-operative and calm by providing adequate analgesia and anxiolytics. Several analgesics such as Fentanyl, alfentanyl, Remifentanil and sedatives like Midazolam and Propofol have been used for AFOI [2] [3] [4]. It is always feared that these drugs may cause respiratory depression and change the sensorium resulting in adverse effects such as hypoxemia and airway obstruction [5] [6] [7]. Therefore, there is a need to find alternative sedative adjunct to fiberoptic intubation under topical anesthesia without affecting the sensorium or compromising airway with patient safety. Recently, Dexmedetomidine, a selective $\alpha 2$ agonist that provides both analgesia and sedation without causing respiratory depression or airway obstruction has been tried for AFOI [8] [9] [10]. Dexmedetomidine has many properties make it a suitable drug for use in managing patients with difficult airways and it is easy when used as a sole agent or an adjuvant, it is efficacious for conscious sedation [11] [12] [13]. Dexmedetomidine has no effect on respiration when used alone, in spite of its ability to produce deep levels of sedation [10] [14] [15]. Moreover Dexmedetomidine facilitates a decrease in salivary secretions, which is a desirable effect during fiberoptic intubation [10]. In the present work, an attempt has been done to study the safety and usefulness of Dexmedetomidine in patients with an elective awake fibro optic nasal intubation in patients were anticipated difficult intubation and to compare the efficacy of Dexmedetomidine for AFOI with that of sedation regimen of Fentanyl. The secondary objective was to compare the hemodynamic response and complications between these two sedative regimens.

\section{Patients and Methods}

After obtaining institutional ethics committee approval and written informed consent from study subjects, this double blinded randomized prospective study was conducted among 60 patients in Aswan University Hospital from October 2016 to October 2017 were anticipated difficult intubation after assessment by modified Malampatti grading (MP) and thyromental distance (TMD). MP grade III and IV and TMD $<6.5 \mathrm{~cm}$ were of both sex, aged $20-40$ years, belonging to 
American Society of Anesthesiologists physical status (ASA-PS) I and II, and posted for elective abdominal surgeries, maxillofacial surgeries. Based on the result of previous study, we calculated the sample size of at least eight in each group with a power of 0.9 and type one error of 0.05 . Due to availability of logistic support 30 patients were taken in each group as there is no upper limit of sample size. Patients were allocated by computer generated random numbers and were divided into two groups. Group A-dexmedetomidine group $(\mathrm{n}=30)$ [D] and Group B-fentanyl group $(\mathrm{n}=30)$ [F]. Dose of study drug was calculated according to patient's body weight, diluted with normal saline to make equal volume of $50 \mathrm{ml}$ and enveloped according to patient's inclusion number by another one. The anesthesiologist preparing the study drug and the observer anesthesiologists were blinded to each other. Fibroscopy was performed by a single anesthesiologist in all patients. The anesthesiologist who performed AFOI and who recorded data were all blinded to the group identities. Patients were pre-medicated with tab. ranitidine $150 \mathrm{mg}$ night before surgery and ondansetron $4 \mathrm{mg}$ on the morning $2 \mathrm{~h}$ before surgery. Injection atropine $1 \mathrm{mg}$ IM $30-60$ min. before surgery. In the operating room, intravenous line (i.v.) was secured with wide bore cannula $(18 \mathrm{G})$ and multichannel monitor was applied to record baseline Heart rate (HR), Mean arterial pressure (MAP), $\mathrm{SpO}_{2}$ and electrocardiogram. Patency of both nostrils was tested and the nostril with better patency was chosen for awake nasal fiberoptic intubation. Topicalization of both the upper and lower airway was accomplished by nebulization with $2 \%$ lidocaine $4 \mathrm{ml}$ (80 mg) for $20 \mathrm{~min}$. Xylometazoline nasal drops and lidocaine jelly were applied to both the nostrils. Tongue and hypopharynx were sprayed with two puffs of $10 \%$ lidocaine $(20 \mathrm{mg})$. After that both drugs was diluted with $50 \mathrm{ml}$ normal saline to be infused over 10 minutes dexmedetomidine $(1 \mathrm{mcg} / \mathrm{kg}$ over $10 \mathrm{~min})$ and fentanyl ( $2 \mathrm{mcg} / \mathrm{kg}$ over $10 \mathrm{~min})$ was infused according to the subject's inclusion number. After lubrication endoscope was loaded with appropriate size cuffed endotracheal tube. At the end of drug infusion, sedation was evaluated by Ramsay sedation scale (RSS) [7]. Level of sedation was evaluated by Ramsay sedation score (RSS) just after completion of infusion of drug as: $1=$ Anxious, agitated or restless, 2 = cooperative, oriented and tranquil, $3=$ sedated but responds to command, $4=$ asleep, brisk glabellar reflex responds to loud noise, $5=$ asleep, sluggish glabellar reflex or responds to loud noise, $6=$ asleep with no response to a painful stimulus. After achieving Score $\geq 2$, fibroscopy was performed through nasal approach. Intubation condition was evaluated by cough score during fibroscopy as Score $1=$ no cough, $2=$ slight cough (no more than two cough in sequence), $3=$ moderate cough ( $3-5$ cough in sequence), $4=$ severe cough ( $>5$ cough in sequence) [11]. Tolerance to intubation was evaluated by post-intubation score after placement of tube in the trachea as: $1=$ Co-operative, 2 = minimal resistance, $3=$ severe resistance [12]. After proper placement of tube in trachea general anesthesia was induced and surgery was allowed to proceed. MAP and HR were noted as a baseline and immediately after intubation. Hypotension (reduction of MAP $>20 \%$ from baseline) was treated with i.v. 
fluid and/or ephedrine $10 \mathrm{mg}$ i.v. bolus, repeat dose after $5 \mathrm{~min}$. Bradycardia $(\mathrm{HR}<60$ beats/min) was treated with atropine $0.6 \mathrm{mg}$ i.v. Oxygen desaturation $\left(\mathrm{SpO}_{2}<95 \%\right.$ for $\left.>10 \mathrm{~s}\right)$ was treated with oxygen supplementation either through a nasal cannula or oxygen port of fibroscopy. Exclusion criteria: We exclude $\mathrm{Pa}$ tients with pregnancy, known alcoholic or drug abusers, allergy to the drugs involved in the study, bradycardia (baseline HR $<60$ beats $/ \mathrm{min}$ ), any type of atrioventricular block, heart failure, having significant neurological, hepatic, renal and pulmonary disease, emergency surgeries, any contraindication for nasal intubation like thrombocytopenia or coagulopathies were excluded from this study.

\section{Statistical Analysis}

Numerical data were expressed as mean with a standard deviation and categorical data were put into tables. Statistical analyses were carried out using the statistical package for the social sciences 16.0 statistical software packages. Numerical data were compared between two groups using independent t-test and within the same group using paired t-test. Categorical data were compared between two groups using Chi-square test. All analysis was two tailed and $\mathrm{P}<0.05$ was considered statistically significant.

\section{Results}

Flow Diagram (Figure 1).

Demographic characteristics like age, weight and ASA-PS(I/II) were comparable between two groups Table 1 .

Cough score $\leq 2$ was considered as favorable intubation condition, which was achieved in 25 out of 30 patients in Group A, but only in 2 out of 30 patients in Group B. The difference was statistically significant $(\mathrm{P}<0.0001)$ as illustrated in Table 2 and Figure 2.

Better post-intubation score (Score 1) was found in 24 patients of Group A and only two patients in Group B. This difference was also statistically significant $(\mathrm{P}<0.0001)$ as illustrated in Table 2 and Figure 3.

At the end of drug infusion, higher RSS was achieved in Group A ( $3 \pm 0.371)$ than in Group B $(2.1 \pm 0.254)(\mathrm{P}<0.0001)$. as illustrated in Table 2 and Figure 4.

We observed that 28 patients of Group A and only five patients in Group B

Table 1. Demographic data.

\begin{tabular}{cccc}
\hline Variables & \multicolumn{2}{c}{ Mean \pm SD } & P value \\
\hline & $\begin{array}{c}\text { Group A } \\
\text { (dexmedetomidine) }\end{array}$ & $\begin{array}{c}\text { Group B } \\
\text { (fentanyl) }\end{array}$ \\
Age (years) & $36.10 \pm 3.273$ & $36.57 \pm 3.115$ & 0.574 \\
Weight (kg) & $49.8 \pm 3.652$ & $49.73 \pm 3.523$ & 0.943 \\
ASA-PS (I/II) & $24 / 6$ & $26 / 4$ & 0.739
\end{tabular}

$\mathrm{SD}=$ standard deviation, ASA-PS = American society of anesthesiology physical status. 


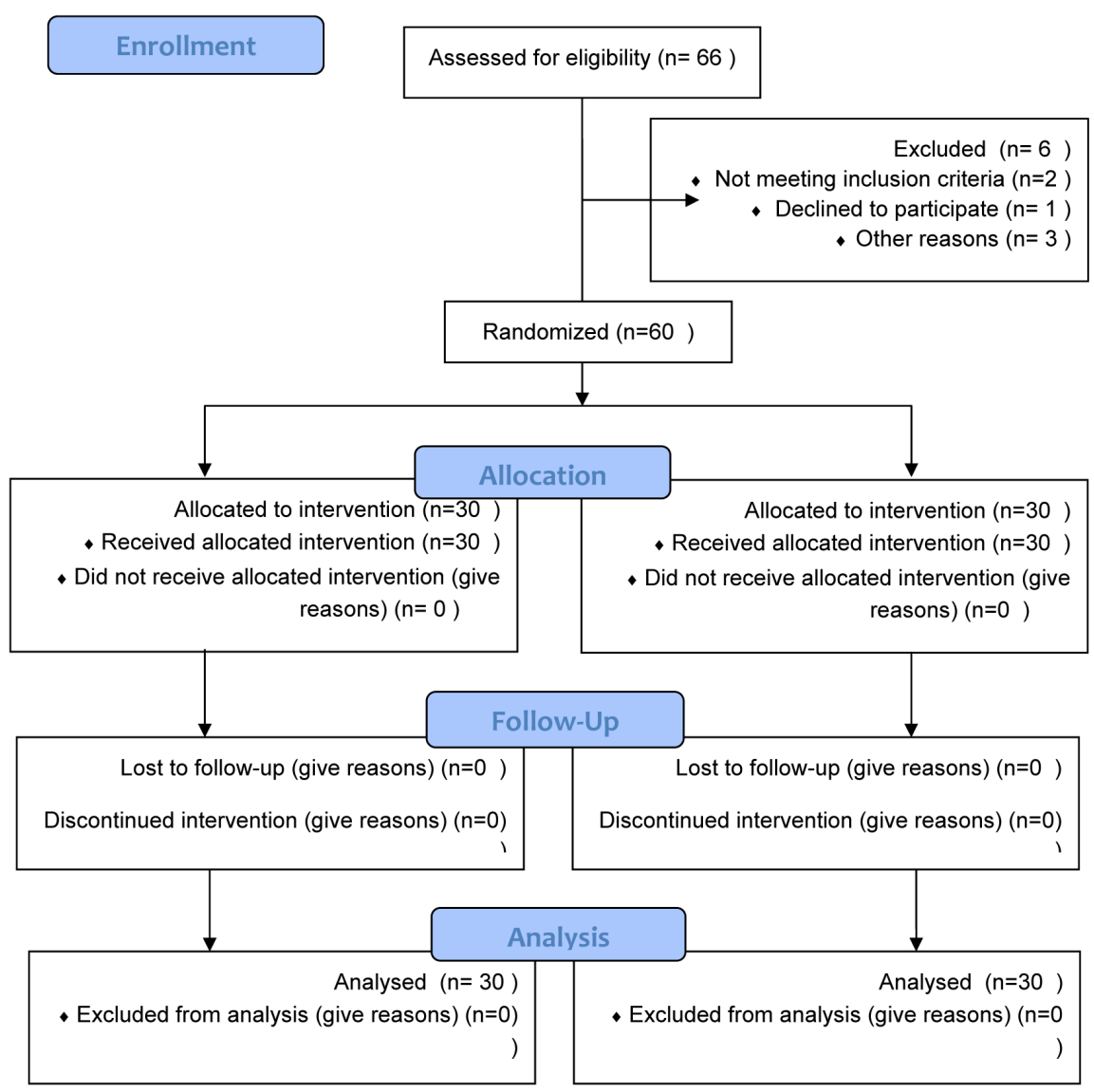

Figure 1. Consort flow diagram.

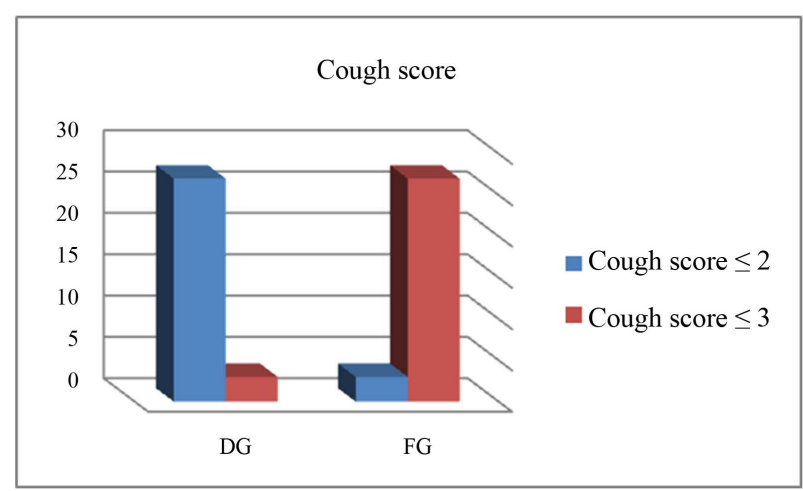

Figure 2. Cough score.

were able to maintain $\mathrm{SpO}_{2}(\geq 95 \%)(\mathrm{P}<0.0001)$ during the procedure. 25 patients in Group B and tow patients in Group A suffered from significant desaturation $\left(\mathrm{SpO}_{2} \leq 94 \%\right)$, which was managed by administration of oxygen through the port of the fibroscopy as illustrated in Table 2 and Figure 5.

The baseline MAP, HR and $\mathrm{SpO}_{2}$ were comparable between two groups (Table 3). There was a rise of MAP compared with baseline values in both groups.

The increase of MAP was minimal in Group A [93 to 96] relatively ( $\mathrm{P}=$ 0.347). However, in Group B rise of MAP was statistically significant [92 to 118] 


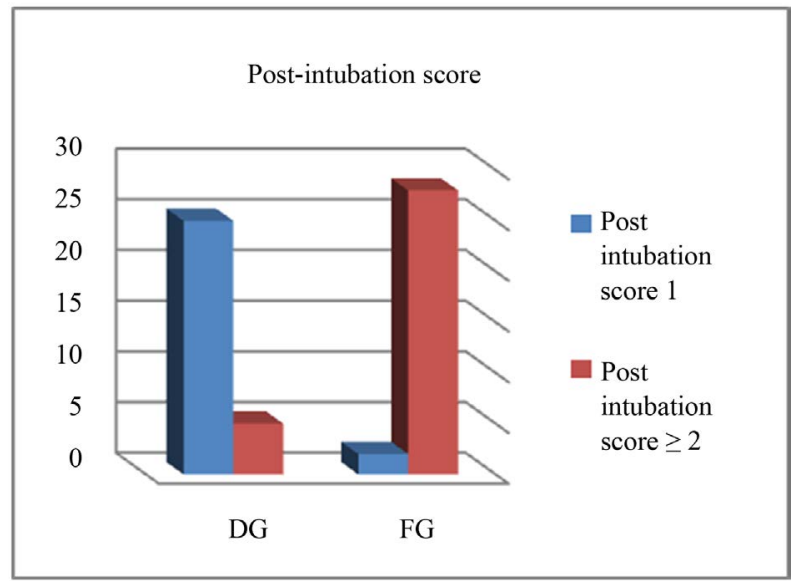

Figure 3. Post-intubation score.

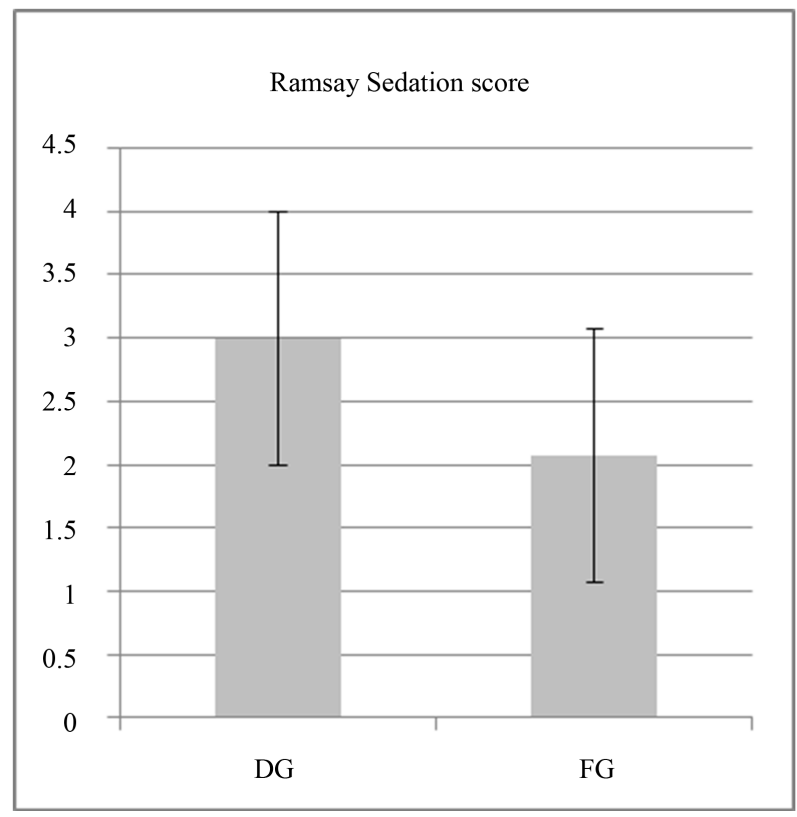

Figure 4. Sedation score.

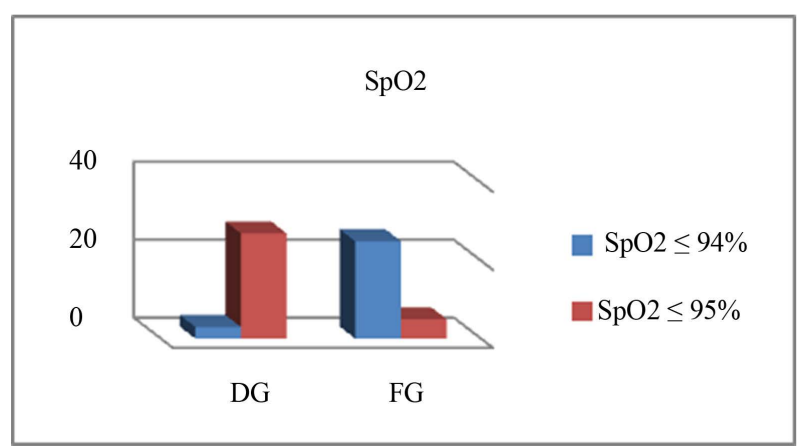

Figure 5. $\mathrm{SpO}_{2}$.

relatively $(\mathrm{P}<0.0001)$ as illustrated in Figure 6. There was no episode of hypotension in both groups. 


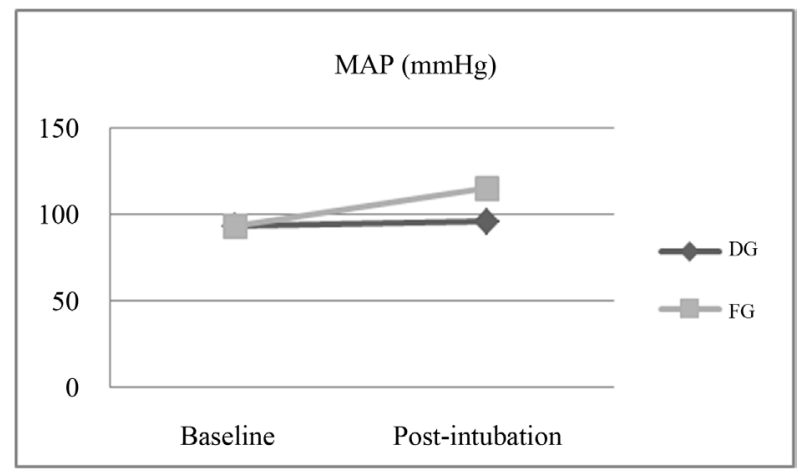

Figure 6. Baseline and post-intubation MAP.

Table 2. Cough score, post-intubation score, sedation score, $\mathrm{SpO}_{2}$.

\begin{tabular}{cccc}
\hline $\begin{array}{c}\text { Intubation and } \\
\text { Post intubation parameter }\end{array}$ & $\begin{array}{c}\text { Group A } \\
\text { (dexmedetomidine Group) }\end{array}$ & $\begin{array}{c}\text { Group B } \\
\text { (fentanyl Group) }\end{array}$ & P value \\
\hline Cough score $\leq 2$ & 25 & 2 & $<0.0001$ \\
Cough score $\geq 3$ & 5 & 28 & $<0.0001$ \\
Post intubation score 1 & 24 & 2 & $<0.0001$ \\
Post intubation score $\geq 2$ & 6 & 28 & $<0.0001$ \\
Ramsay sedation scale(RSS) & & & \\
$\mathrm{SpO}_{2} \leq 94 \%$ & $3 \pm 0.371$ & $2.1 \pm 0.254$ & $<0.0001$ \\
$\mathrm{SpO}_{2} \geq 95 \%$ & 2 & 25 & $<0.0001$ \\
$\mathrm{SpO}_{2}=\mathrm{Oxygnen}$ saturation & 28 & 5 & $<0.0001$ \\
\hline
\end{tabular}

Table 3. Baseline and post-intubation MAP, baseline and post-intubation HR.

\begin{tabular}{cccc}
\hline $\begin{array}{c}\text { Hemodynamic } \\
\text { Parameter }\end{array}$ & $\begin{array}{c}\text { Group A } \\
\text { (dexmedetomidine Group) }\end{array}$ & $\begin{array}{c}\text { Group B } \\
\text { (fentanyl Group) }\end{array}$ & P value \\
\hline $\begin{array}{c}\text { Base line MAP } \\
\text { (mean } \pm \text { SD) } \\
\text { (mm of Hg) }\end{array}$ & $93.43 \pm 6.668$ & $92.34 \pm 4.904$ & 0.895 \\
Post intubation & $96.03 \pm 4.83$ & $118.18 \pm 11.2$ & \\
MAP (mean \pm SD) & & & \\
(mm of Hg) & 0.347 & $<0.0001$ & \\
P value & & $77.767 \pm 10.562$ & \\
Base line HR \\
(mean \pm SD) \\
(beat/min)
\end{tabular}

$\mathrm{SD}=$ Stander deviation, $\mathrm{MAP}=$ Mean arterial pressure, $\mathrm{HR}=$ Heart rate.

There was a significant increase in HR in the post-intubation period (114 \pm 16.482 beats $/ \mathrm{min})$ in comparison with the baseline value $(77.767 \pm 10.562$ beats/min $)$ in Group F $(\mathrm{P}<0.0001)$. The post-intubation HR $(71 \pm 6.48$ 
beats/min) decreased significantly in comparison with baseline value (77.466 \pm 5.75 beats/min) in Group D (P value 0.005) as illustrated in Figure 7. However, no patient developed bradycardia ( $\mathrm{HR}<60$ beats/min) requiring atropine.

\section{Discussion}

Awake intubation is primary or alternate options in difficult airway situations. Now-a-days, AFOI is the preferred method for securing a difficult airway. Various drugs have been tried to achieve conscious sedation during AFOI. Fentanyl synthetic opioid, provides mild sedation, analgesia along with hemodynamic stability, which are beneficial for AFOI but there is a risk of respiratory depression, nausea and vomiting and chest wall rigidity [10] [14] [15]. Dexmedetomidine is a highly selective, centrally acting presynaptic $\alpha$-2 receptors to provide negative feedback causing less neurotransmitter (norepinephrine, epinephrine) which sedates through its action on the locus coeruleus, the predominant noradrenergic nucleus in the brain [10]. Dexmedetomidine sedation in AFOI would attenuate hemodynamic responses without respiratory depression, [13]. It produces hypnosis, amnesia, analgesia, anxiolysis, sympatholysis and antisialogogue effects all of which are desirable during AFOI [14]. Dexmedetomidine induces sedation involving activation of endogenous sleep promoting pathway through the post-synaptic $\alpha$-2 receptors in the locus ceruleus, which modulates wakefulness. The major advantages of dexmedetomidine infusion during AFOI are a unique form of sedation where patients remain sleepy, but are easily aroused, cooperative with minimum respiratory impairment. The feasibility of dexmedetomidine has been recently studied either as a sole sedative agent or as an adjuvant during AFOI [15] [16]. In this study we compared dexmedetomidine 1 $\mathrm{mcg} / \mathrm{kg}$ (Group A) with fentanyl $2 \mathrm{mcg} / \mathrm{kg}$ (Group B) and found more favorable intubation conditions and better tolerance to intubation in dexmedetomidine group than fentanyl group. cough score was $\leq 2$ in 25 patient in group D compared with 2 patient in group $\mathrm{F}$, better post intubation score (score 1) in group $\mathrm{D}$ was 24 Vs. 2 in group F, mean Ramsy sedation score in group D was $3 \pm 0.371$ Vs. $2.1 \pm 0.254$ in group F, Spo $2 \geq 95 \%$ in group D was 28 Vs. 5 patient in group $\mathrm{F}$, insignificant rise in MAP from $93.43 \pm 6.668$ to $96.03 \pm 4.83 \mathrm{mmhg}$ in group $\mathrm{D}(\mathrm{p}=0.347)$, but there was significant rise from $93.23 \pm 4.904$ to118.18 \pm 11.2

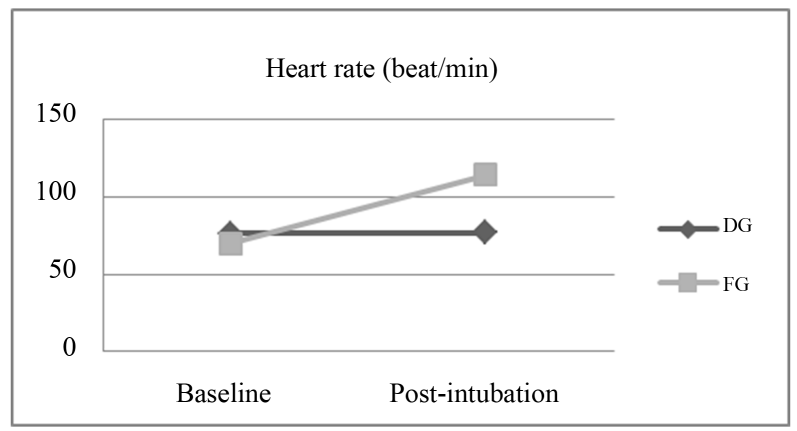

Figure 7. Baseline and post-intubation HR. 
$(\mathrm{P} \leq 0.0001)$ in group $\mathrm{F}$, there was significant decrease in HR from 77.4 to 71 ( $\mathrm{P}$ $=0.005)$ in group $\mathrm{D}$ vs. significant rise from 77 to $114(\mathrm{P} \leq 0.0001)$ in group $\mathrm{F}$. Bergese et al. [4] noted that dexmedetomidine at $1 \mathrm{mcg} / \mathrm{kg}$ bolus was safe and beneficial for patients undergoing AFOI even without airway nerve block or topical anesthesia. Avitsian et al. [14] Presented a clinical case series of patients who underwent an awake fiberoptic endotracheal intubation (AFOI) using dexmedetomidine for sedation. Adequate sedation in addition to topicalization of the airway might be the key to minimize patient discomfort and assists in successful intubation. Chu et al. [10] observed better tolerance to intubation without respiratory depression and upper airway obstruction in dexmedetomidine group $(1 \mathrm{mcg} / \mathrm{kg})$ compared with fentanyl group $(1 \mathrm{mcg} / \mathrm{kg})$. In our study, dexmedetomidine produced better intubating conditions than fentanyl used in dose of $2 \mathrm{mcg} / \mathrm{kg}$. Dexmedetomidine has also been proved as an effective agent for AFOI in certain difficult airway [14] [15] [16]. Hu et al. [15] conducted a double-blinded, randomized controlled trial comparing dexmedetomidine versus remifentanil sedation during awake fiberoptic nasotracheal intubation in 40 patients. Compared with remifentanil, dexmedetomidine offered better endoscopy scores, lower recall of intubation, and greater patient satisfaction, with minimal hemodynamic side effects. Ryu et al. [17] compared remifentanil with dexmedetomidine for conscious sedation during bronchoscopy. They found that there were no significant difference of sedation level, MAP, HR and patient satisfaction score $(P>0.05)$ but cough score and incidence of desaturation was significantly lower $(P<0.01)$ in dexmedetomidine group than remifentanil group. In our study, patients of dexmedetomidine group showed better hemodynamic stability. Initial HR and MAP were similar in both groups. The increase of MAP was minimal in Group D [93 to 96] relatively $(P=0.347)$. However, in Group F rise of MAP was statistically significant [93 to 118] relatively ( $\mathrm{P}<$ 0.0001). There was no episode of hypotension in both groups. There was a significant change of $\mathrm{HR}$ in the post-intubation period in comparison with the baseline value in Group F, which was statistically significant $(\mathrm{P}<0.0001)$. However, there was no significant changes of $\mathrm{HR}$ in the post-intubation period in comparison with baseline value in Group D. There was no incidence of bradycardia in any patient. PL Bailey et al. observed that Fentanyl alone produced hypoxemia in half of the subjects and significant depression of the ventilatory response to Carbon-dioxide but did not produced apnea. Dexmedetomidine has no effect on respiratory center therefore devoid of any deleterious effect on respiratory rate and $\mathrm{SPO}_{2}$ and therefore it is an attractive choice for AFOI. In our study we observed that 28 patients of Group A and only five patients in Group B were able to maintain $\mathrm{SpO}_{2}(\geq 95 \%)(\mathrm{P}<0.0001)$ during the procedure. 25 patients in Group B and tow patients in Group A suffered from significant desaturation $\left(\mathrm{SpO}_{2} \leq 94 \%\right)$, which was managed by administration of oxygen through the port of the fibroscopy. Bergese et al. [4] found that dexmedetomidine in combination with low dose midazolam is more effective than midazolam alone 
for sedation in AFOI. However, dexmedetomidine dose in excess of $1 \mathrm{mcg} / \mathrm{kg} / \mathrm{h}$ with midazolam produced airway obstruction, which was managed by simple chin lift. In our study, all patients achieved RSS $\geq 2$, but patients of Group D achieved a higher score $(3 \pm 0.371)$ than Group F $(2.1 \pm 0.254)(P<0.0001)$. Inspite of our precautionary measure few patients had nasal bleed. In the present study nasal approach to fiberoptic intubation was used because it is relatively easier than the oral approach. Sore throat occurred in 4 patients of group $\mathrm{D}$ and 7 patients of group F. None of the patient had hoarseness or dysphagia. Adverse effects during our study were very minimal adverse effects. They concluded that dexmedetomidine provided adequate sedation and patients gave excellent cooperation for post-intubation.

\section{Conclusion}

In conclusion, the dexmedetomidine and fentanyl infusions utilized in our study provided satisfactory sedation and intubating conditions in the majority of patients undergoing fiberoptic nasal intubation. Dexmedetomidine appeared to offer better patient tolerance, better preservation of a patent airway, spontaneous ventilation, and a reduced hemodynamic response to intubation, in comparison to fentanyl. These properties make it a useful drug for providing conscious sedation, and combination of dexmedetomidine sedation with topical anesthesia provides significant benefit for awake fiberoptic.

\section{Conflict of Interest}

The authors declare that they have no conflict of interest.

\section{References}

[1] Popat, M. (2001) Practical Fibroptic Intubation. Butterworth-Heinemann Publishers, Oxford, 75-95.

[2] Song, J.W., Kwak, Y.L., Lee, J.W., Chang, C.H., Kim, H.S. and Shim, Y.H. (2012) The Optimal Effect Site Concentration of Remifentanil in Combination with Intravenous Midazolam and Topical Lidocaine for Awake Fiberoptic Nasotracheal Intubation in Patients Undergoing Cervical Spine Surgery. Minerva Anestesiologica, 78, 521-526.

[3] Dhasmana, S., Singh, V. and Pal, U.S. (2010) Awake Blind Nasotracheal Intubation in Temporomandibular Joint Ankylosis Patients under Conscious Sedation Using Fentanyl and Midazolam. Journal of Maxillofacial and Oral Surgery, 9, 377-381. https://doi.org/10.1007/s12663-010-0159-8

[4] Bergese, S.D., Patrick Bender, S., McSweeney, T.D., Fernandez, S., Dzwonczyk, R. and Sage, K. (2010) A Comparative Study of Dexmedetomidine with Midazolam and Midazolam Alone for Sedation during Elective Awake Fiberoptic Intubation. Journal of Clinical Anesthesia, 22, 35-40. https://doi.org/10.1016/j.jclinane.2009.02.016

[5] Zhang, X., He, W., Wu, X., Zhou, X., Huang, W. and Feng, X. (2012) TCI Remifentanil vs. TCI Propofol for Awake Fiber-Optic Intubation with Limited Topical Anesthesia. International Journal of Clinical Pharmacology and Therapeutics, 50, 
10-16. https://doi.org/10.5414/CP201580

[6] Bailey, P.L., Pace, N.L., Ashburn, M.A., Moll, J.W., East, K.A. and Stanley, T.H. (1990) Frequent Hypoxemia and Apnea after Sedation with Fentanyl and Midazolam. Anesthesiology, 73, 826-830.

https://doi.org/10.1097/00000542-199011000-00005

[7] Rai, M.R., Parry, T.M., Dombrovskis, A. and Warner, O.J. (2008) Remifentanil Target-Controlled Infusion vs. Propofol Target Controlled Infusion for Conscious Sedation for Awake Fibreoptic Intubation: A Doubleblind Randomised Controlled Trial. British Journal of Anaesthesia, 100, 125-130.

[8] American Society of Anesthesiologists Task Force on Management of the Difficult Airway (2003) Practice Guidelines for Management of the Difficult Airway: An Updated Report by the American Society of Anesthesiologists Task Force on Management of the Difficult Airway. Anesthesiology, 98, 1269-1277.

https://doi.org/10.1097/00000542-200305000-00032

[9] Wang, S.Y., Mei, Y., Sheng, H., Li, Y., Han, R., Quan, C.X., et al. (2013) Tramadol Combined with Fentanyl in Awake Endotracheal Intubation. Journal of Thoracic Disease, 5, 270-277.

[10] Chu, K.S., Wang, F.Y., Hsu, H.T., Lu, I.C., Wang, H.M. and Tsai, C.J. (2010) The Effectiveness of Dexmedetomidine Infusion for Sedating Oral Cancer Patients Undergoing Awake Fibreoptic Nasal Intubation. European Journal of Anaesthesiology, 27, 36-40. https://doi.org/10.1097/EJA.0b013e32832e0d2b

[11] Hall, J.E., Uhrich, T.D., Barney, J.A., Arain, S.R. and Ebert, T.J. (2000) Sedative, Amnestic, and Analgesic Properties of Small-Dose Dexmedetomidine Infusions. Anesthesia \& Analgesia, 90, 699-705. https://doi.org/10.1097/00000539-200003000-00035

[12] Avitsian, R., Lin, J., Lotto, M. and Ebrahim, Z. (2005) Dexmedetomidine and Awake Fiberoptic Intubation for Possible Cervical Spine Myelopathy: A Clinical Series. Journal of Neurosurgical Anesthesiology, 17, 97-99. https://doi.org/10.1097/01.ana.0000161268.01279.ba

[13] Neumann, M.M., Davio, M.B., Macknet, M.R. and Applegate, R.L. (2009) 2nd Dexmedetomidine for Awake Fiberoptic Intubation in a Parturient with Spinal Muscular Atrophy Type III for Cesarean Delivery. International Journal of Obstetric Anesthesia, 18, 403-407. https://doi.org/10.1016/j.ijoa.2009.05.002

[14] Maroof, M., Khan, R.M., Jain, D. and Ashraf, M. (2005) Dexmedetomidine Is a Useful Adjunct for Awake Intubation. Canadian Journal of Anesthesia, 52, 776-777. https://doi.org/10.1007/BF03016576

[15] Grant, S.A., Breslin, D.S., MacLeod, D.B., Gleason, D. and Martin, G. (2004) Dexmedetomidine Infusion for Sedation during Fiberoptic Intubation: A Report of Three Cases. Journal of Clinical Anesthesia, 16, 124-126. https://doi.org/10.1016/j.jclinane.2003.05.010

[16] Stamenkovic, D.M. and Hassid, M. (2006) Dexmedetomidine for Fiberoptic Intubation of a Patient with Severe Mental Retardation and Atlantoaxial Instability. Acta Anaesthesiologica Scandinavica, 50, 1314-1315. https://doi.org/10.1111/j.1399-6576.2006.01157.x

[17] Ryu, J.H., Lee, S.W., Lee, J.H., Lee, E.H., Do, S.H. and Kim, C.S. (2012) Randomized Double-Blind Study of Remifentanil and Dexmedetomidine for Flexible Bronchoscopy. British Journal of Anaesthesia, 108, 503-511.

https://doi.org/10.1093/bja/aer400 